\title{
Editorial 23/1
}

\section{Rainer Alt • Hubert Österle}

Published online: 6 February 2013

(C) Institute of Information Management, University of St. Gallen 2013

Dear readers of Electronic Markets,

With the population of mobile Internet devices exceeding the human population, new potentials are emerging for actors along the value chain. The points where information is originated become directly linked with the points where information is used - either by businesses or consumers. We are not only experiencing new business segments and models for mobile technologies, such as smartphones, tablets and the like, but for a realm of services which encompass the operation of platforms, such as service marketplaces ("app stores or marketplaces"), the user interfaces ("iTunes or Play") and, in particular, numerous services which are traded via these markets and used via these interfaces. The intelligence of mobile devices is not limited to multi-core processors and large memory capacities but also includes various capabilities for sensors and other enhancements. Thus, the future will increasingly see location-based services which are dependent on the user's context.

This special issue presents an application domain where mobile devices are paving the way for new services between service providers and users. While traditional perspectives on this sector are heavily influenced by the medical profession, new developments are showing that the "illness" perspective needs to be complemented by a "well-being" perspective. Analogous to the past transformation of established industries, such as the media industry, the blurring boundaries between the medical and the tourism sector will lead to

\footnotetext{
R. Alt $(\bowtie)$

University of Leipzig, Grimmaische Str. 12,

04109 Leipzig, Germany

e-mail: rainer.alt@uni-leipzig.de

H. Österle

University of St. Gallen, Müller-Friedberg-Str 8,

9000 St. Gallen, Switzerland

e-mail: hubert.oesterle@unisg.ch
}

threats and opportunities alike. However, from the consumer's perspective this convergence refers only to one living environment. Others, such as housing and money, need to be coordinated and will lead to a new consumer-driven view on services. For sure, many years of research will be required in practice and academia before the solutions are able to face the ultimate challenge of adoption by users.

The five research papers in the special theme section provide valuable insights regarding the forthcoming potentials of location-based services enabled by mobile technologies and the critical issue of their diffusion among hospitals, physicians, and, especially, the patients themselves. We are indebted to the guest editors, Doug Vogel, Dennis Viehland, Nilmini Wickramasinghe and Joseph M. Mula, who made this special issue possible. They will introduce the five articles in their preface.

In addition to the special theme papers, the present issue comprises one general research contribution which addresses customer-orientation from a business perspective and pursues the questions relating to "The optimal level of CRM IT investments". Following a design science approach, the authors, Julia Heidemann, Mathias Klier, Andrea Landherr, and Steffen Zimmermann, have developed an optimization model which supports companies in determining the economic impact of their investments in Customer Relationship Management systems (CRM). They argue that instead of implementing full-scale CRM-systems, companies should focus on the critical, i.e. value creating, functionalities. A case study from a German financial services provider illustrates the model as well as its benefits.

We thank all editors and reviewers who were involved in this issue and hope you enjoy reading it!

Best regards from Leipzig and St. Gallen,

Rainer Alt

Hubert Österle 